\title{
The Potential Effect of the 21st Century Cures Act on Drug Development
}

\author{
Joseph A. Goble, PharmD, MS
}

\begin{abstract}
SUMMARY
Enacted in December 2016, the 21st Century Cures Act is a pivotal piece of legislation that will influence the FDA drug and device approval process for the foreseeable future. Although this legislation received overwhelming support by members of Congress for much needed budgetary increases for the FDA and other national health organizations, there is much controversy over certain provisions that potentially diminish the robustness of the evidence base required for drug and medical device approvals. This article discusses the key provisions from "Title III-Development" under "Division A-21st Century Cures" related to drug development and, specifically, explores those aspects that address patient-focused drug development, use of surrogate endpoints in clinical trials, modernization of trial design, and use of real-world evidence for decision making and health care economic information. In addition, specific legislation on regulatory changes is discussed pertaining to antimicrobial stewardship. Essentially, summarized interpretations are presented here of the provisions covering the aforementioned topics, along with insights into potential intended and unintended consequences for U.S. health care payers, health care providers, government entities, and product manufacturers.
\end{abstract}

J Manag Care Spec Pharm. 2018;24(7):677-81

Copyright $\odot 2018$, Academy of Managed Care Pharmacy. All rights reserved.

$\mathrm{O}$ n December 13, 2016, an unprecedented piece of legislation, the 21st Century Cures Act, was signed into law with the intention to "accelerate the discovery, development, and delivery" of therapies aimed to cure prominent diseases plaguing society heading into the 21 st century. ${ }^{1}$ Several patient advocacy groups, drug and device manufacturers, and government research entities have touted the bill as a serious commitment of the U.S. government to bring more innovative and curative medicines to patients. The Cures Act may lead to such lofty accomplishments but not without potentially serious unintended consequences. For example, the majority of funding for National Institutes of Health innovative research projects seeking cures for cancer, Alzheimer's disease, and other high-impact illnesses is derived by removing $\$ 3.5$ billion from the Prevention and Public Health Fund (PPHF), which was initially established by the Affordable Care Act (ACA). ${ }^{1}$ The effect of the PPHF has been far reaching, with substantial allocations dedicated to immunizations, chronic illness prevention, and preventative health services. ${ }^{2}$

Perhaps the most controversial section of the Cures Act pertains to certain provisions set forth to modernize regulations for new drug and device development that were intended to streamline the U.S. Food and Drug Administration (FDA) review of applications in a more "industry-friendly" manner Concern has arisen from potential "shortcuts" created for manufacturer submissions to the FDA, calling into question the robustness of the evidence required for new drug (or new indications for an existing drug) approvals. While uncertainty exists with policymaker handling of these evidence types, expedited access to truly effective drugs may confer net benefits under these regulatory conditions. ${ }^{3,4}$

In 1962, drug development in the United States achieved a historic milestone with the passage of the Kefauver-Harris Drug Amendments to the Federal Food Drug \& Cosmetic Act, which enhanced FDA oversight of drug evaluations to ensure efficacy and safety. ${ }^{5}$ Consequently, Republicans have faulted the administrative burden of FDA review for the lengthy discovery-to-launch timeline for medications. Today, the FDA is approving drugs quicker than at almost any other point in the past 25 years. ${ }^{6}$ As of 2016, the median approval time for standard new drug applications was 10.1 months (down from 26.9 months in 1993), ${ }^{7}$ with the decrease largely attributable to an increase in review staff support and funding through the Prescription Drug User Fee Act in 2017.,8 Nonetheless, this reduction in approval time does not preclude manufacturers from expressing concern regarding a burdensome submission process that may be relieved by the Cures Act.

While many of the evidence evaluation provisions will take several years to implement, careful consideration must be given regarding the future of disease management in the United States. Thus, the purpose of this article is to review the 21st Century Cures Act and discuss its implications for the future of medications and their key stakeholders. Specifically, this article explores provisions related to drug development and the generation of new evidence supporting new product approvals in "Title III-Development" under "Division A-21st Century Cures," as well as their anticipated and unanticipated consequences.

\section{Patient-Focused Drug Development}

Subtitle A under Title III of the Cures Act charges the Secretary of the Department of Health and Human Services (HHS) with the development of formal guidance on the collection and submission of patient experience data to the FDA. ${ }^{1}$ The FDA is required to include a statement in the product labeling regarding any patient experience data that was used for drug approval. Emphasis is placed 
on patient engagement in all phases of the data process (i.e., collection, reporting, management, and analysis) to capture true patient perspectives regarding burden of disease, treatment experience, and burden of treatment. Patients are given the opportunity to submit proposals to influence the FDA's draft guidance process. By 2021, the FDA will also be required to generate its first in a series of reports based on review of patient experience data and information on patientfocused drug development tools, also known as patientreported outcomes (PROs), for new approved drugs.

While patient involvement in the drug development process is not a novel concept, the FDA mandate may bolster patient-centered research efforts and bring groups such as the Patient-Centered Outcomes Research Institute (PCORI) to the forefront. Although PCORI has no authority to mandate coverage decision criteria for U.S. payers, the "PCORI Methodology Report" contains standards for conducting patient-centered outcomes research, including navigation of PROs in comparative effectiveness studies. This report has guided the proceedings of over $\$ 1.4$ billion in funded projects since the group's inception as part of the ACA in 2010 and may serve as a key reference in anticipation of the FDA guidance. ${ }^{9}$ Also, patientcentered outcomes and their use in discerning the value of treatment have been explored in several emerging value-based frameworks, which attempt to evaluate drugs to aid in payer, physician, and patient decisions regarding treatment. In frameworks such as that developed by the American Society of Clinical Oncology, patient experience data may provide higher value to drugs that show meaningful improvements in domains such as symptom palliation or treatment-free intervals. ${ }^{10}$ The provisions in Subtitle A may lead to the consistent incorporation of PROs in clinical trials and facilitate well-informed patient decision making for outcomes relevant to their diseases.

\section{Advancing New Drug Therapies}

Surrogate endpoints, such as physical signs of disease, laboratory measures, and radiological tests, are disease indicators intended to substitute for clinical outcomes. ${ }^{11}$ While the importance of patient experience data in clinical studies is self-evident, consensus on the proposed streamlining of surrogate endpoint use for new drug approvals found in Subtitle B under Title III is highly unlikely. Subtitle B focuses on accelerating the drug approval process and is perhaps the most controversial provision because of the consideration of certain evidence types - including surrogate endpoints-that call into question the robustness of supporting evidence for new drug approvals. The use of surrogate endpoints in clinical studies may be advantageous when clinical outcomes are difficult to collect or take an unreasonable amount of time to capture. The FDA accepts the use of validated surrogate endpoints for drug approvals, such as hemoglobin Alc in diabetes, which reliably predict or correlate to improvement in patient outcomes. ${ }^{12}$
Their use has become commonplace, with surrogate endpoints representing the primary endpoint in clinical trials for $45 \%$ of new drugs approved between 2010 and 2012. ${ }^{12}$

However, the standardization of an FDA review process for surrogate endpoints for drug development creates several challenges. ${ }^{11,12}$ First, the FDA has previously stated that a primary hurdle to surrogate endpoint use has been a lack of reliable evidence about performance, with 1 study showing that 65\% of potential drug targets or biomarkers have inconsistencies when attempting to reproduce findings. ${ }^{13}$ Also, some surrogate endpoints already implemented for drug approvals have proven to be poor or misleading when the drug is used in real-world settings. One meta-analysis in oncology showed that the correlation between surrogate markers and overall survival was low in $52 \%$ of studies, medium in $25 \%$, and high in only $23 \% .^{14}$ Other literature warns of the dangers of relying solely on surrogate endpoints and cites 14 real-world examples in which an approved drug produced deleterious outcomes for patients. ${ }^{15}$ The inconsistency of surrogate endpoints in postmarketing may be explained by the heterogeneous populations found in these settings. While clinical trials typically enroll a relatively healthy homogeneous population, postmarket drug use occurs in heterogeneous populations having previously excluded comorbidities and reflect larger numbers of patients. This variability could decrease the correlation between the surrogate endpoint and other endpoints in the real world. In the realm of expensive oncology treatments, drugs that are recommended as first-line options but do not prove cost-effective could be financially toxic to the health care system and to patients. ${ }^{16}$ However, companion diagnostics for targeted cancer therapies provide a solution by restricting administration to those patients most likely to benefit from treatment, thereby achieving better outcomes and reducing costs.

\section{Modern Trial Design and Evidence Development}

In addition to the consideration given to surrogate endpoints, Subtitle C under Title III focuses on updating research study designs by enhancing the statistical methodology (e.g., advanced modeling) used for new drug applications. ${ }^{1}$ The opportunity to create powerful analytical tools may improve prediction of treatment effects with better translation of clinical studies to real-world settings. However, uptake of these novel evidence types are predicated on the confidence of payers and physicians who will use them as supplements to coverage decisions and prescribing, respectively. Health care organizations base their coverage determinations on all available peerreviewed published evidence for that product at the time of review. Future advancements in study designs led by the pharmaceutical industry and the FDA must be done with transparency, providing opportunities for those delivering the drugs in real-world settings to gain confidence in the new evidence base. 
Perhaps more contentious is the provision under Subtitle C that enables drug manufacturers to submit real-world evidence (RWE) instead of randomized control trial (RCT) data to seek new indications for existing medications. RWE is clinical practice and utilization data collected outside of the RCT setting and is regarded for its comprehensive patient perspective under circumstances that reflect real-life experiences. ${ }^{17}$ Under the Cures Act, permissible sources of RWE include ongoing surveillance data, observational studies, registries, claims, and patient-centered outcomes research activities. Concerns with the use of RWE for drug approvals-even for established drugs for which RCT data are available-stem from the relatively large number of assumptions necessary to analyze nonrandomized observational data.

Under routine practice conditions, clinicians prescribe drugs to patients in a systematic process that takes into consideration the intrinsic and extrinsic characteristics of the patient and the available drug options. Without randomization (excluding the case of pragmatic clinical trials), the major threat to internal validity of RWE is treatment selection bias. ${ }^{18}$ Information gaps are common in RWE, which poses a challenge when using these data sources for research purposes. Without proper controlling for confounders, RWE can lead to overemphasis of treatment benefits. ${ }^{5}$

In response to the problems with using RWE, international organizations have developed best practice guidelines to address the validity and reproducibility of RWE generation to facilitate a credible evidence base, leveraging health care datasets that reflect real-world patient populations. ${ }^{19,20}$ The collaborations of the nation's most innovative clinical institutions, such as the Health Care Systems Research Network and the National Patient-Centered Clinical Research Network, present an opportunity to spearhead RWE replication efforts. Leveraging "research ready" data systems, these networks have the coordination to operationalize hypotheses of clinical effectiveness across diverse care settings and patient populations to enhance generalizability. However, challenges to mobilize evidence generation for decision makers whose institutions fall outside of these networks remain.

The costs to generate RWE for the approval of new indications will be substantially lower than the costs for traditional RCT evidence generation. Thus, manufacturers are positioned to achieve higher returns on investments when their overhead is reduced by observational studies. With this lower cost threshold for existing products to increase market share through new indications, several scenarios are plausible. ${ }^{21} \mathrm{~A}$ major concern for payers will be coverage decisions without the gold standard RCT evidence base. Innovative contracting methods, such as outcomes-based contracting and indicationbased pricing, have been regarded as potential solutions to coverage when outcomes are uncertain and may capture payment for value. While many of these contracts and partnerships have been publicly announced, there is still a lack of available information on whether these arrangements are living up to expectations. Continued stakeholder commitment and activity in this space has served as a proxy to gauge the success of these endeavors. ${ }^{22-26}$

\section{Patient Access to Therapies and Information}

Section 3037 of the Cures Act addresses the expansion of the scope of health care economic information (HCEI) that may be provided by manufacturers. ${ }^{1}$ First, the law allows manufacturers to promote HCEI that includes or is based on evidence that is not necessarily directly related to the FDA-approved indications of the drug, provided that appropriate disclaimers accompany any presentation of such material. This allowance represents an opportunity for all parties to obtain more valuable information from HCEI, since payers are interested in the actual use of medications in their populations that does not always fit perfectly into the confines of the product labeling. ${ }^{27}$ The Cures Act expands the extent of HCEI that may be promoted to include any analysis and its components (clinical data, inputs, clinical or other assumptions, methods, results, and other components), thus alleviating manufacturer concerns that health economic information will be held to the same level of scrutiny as clinical outcomes information. ${ }^{27}$ However, ambiguity exists regarding the determination of competent and reliable scientific evidence and instances of material differences between HCEI and labeling. This ambiguity creates a crucial opportunity for health economics and outcomes researchers to establish the operational definitions of these concepts. Several national organizations, such as the Academy of Managed Care Pharmacy, have been working diligently with legislators to spearhead initiatives to shine light on the renewed interest for consensus in the exchange of pharmacoeconomic information. ${ }^{28}$

\section{Antimicrobial Innovation and Stewardship}

Another area of focus in the Cures Act is use of antimicrobials. Undoubtedly, antimicrobial resistance has become an emergent issue threatening society's control of infectious diseases. According to the Centers for Disease Control and Prevention (CDC), antimicrobial resistance causes over 2 million episodes of illness and 23,000 deaths annually. ${ }^{29}$ Subtitle E addresses several CDC and FDA initiatives to better track trends and inform health care professionals of best antimicrobial stewardship practices. However, there is a potentially contradictory provision that allows the use of novel antibiotics and antifungals with an unconventional, minimal evidence base (e.g., small studies, preclinical evidence, pharmacokinetic studies, phase II clinical trial data, and other evidence deemed appropriate by the HHS Secretary in lieu of morbidity and mortality data) if indicated for "serious or life-threatening" infections.$^{30}$ While the labeling would carry information warning providers to restrict use to limited populations, previous 
experience suggests such a warning will not deter inappropriate use..$^{5}$ Hospitals may receive a financial bonus for use of these products, which arguably encourages excessive and inappropriate use that may lead to a paradoxical effect of diminished antimicrobial stewardship., ${ }^{5,30}$

\section{Conclusions}

The 21st Century Cures Act places health care innovation at the forefront of the U.S. national agenda. While many of the provisions of this law may take several years to fully materialize, prominent stakeholders will be tasked with ensuring that a hastened approval process for groundbreaking therapies does not come at a detriment to patient safety with approval of ineffective or unsafe products. Approval considerations under a new evidence base will likely have positive and negative implications for manufacturers. While expedited FDA approvals are imminent, the U.S. health system's quest for value in coverage determination remains unresolved. Health care payers will only cover products that demonstrate substantial added benefit to their populations. Future health economic analyses may uncover the true effect of the Cures Act as RWE is incorporated into regulatory decision making. Despite the relief from administrative hurdles that the Cures Act provides, manufacturers will have a responsibility to collaborate with regulatory entities to advance the sophisticated processes of drug development or otherwise jeopardize the integrity of the FDA and hamper efforts to optimize population health.

\section{Author}

JOSEPH A. GOBLE, PharmD, Baylor Scott \& White Health, Temple, Texas, and University of Texas, Health Outcomes and Pharmacy Practice Division, Austin.

AUTHOR CORRESPONDENCE: Joseph A. Goble, PharmD, MS, Department of Pharmacy, Baylor Scott $\&$ White Health, 2401 31st St., MS-Ag-407Q, Temple, TX 76508. Tel.: 908.278.4497; E-mail: Joseph.Goble@BSWHealth.org.

\section{DISCLOSURES}

No outside funding supported this writing. Goble is completing fellowship training sponsored by Novartis Pharmaceuticals.

\section{ACKNOWLEDGMENTS}

The author thanks Kenneth A. Lawson, PhD, for helpful suggestions during the writing of the manuscript.

\section{REFERENCES}

1. U.S. House Energy and Commerce Committee, U.S. Senate HELP Committee. 21st Century Cures Act. November 25, 2016. Available at: http:// docs.house.gov/billsthisweek/20161128/CPRT-114-HPRT-RU00-SAHR34 pdf. Accessed May 5, 2018.

2. U.S. Department of Health and Human Services. Prevention and Public Health Fund. January 2, 2015. Available at: https://www.hhs.gov/open/prevention/index.html. Accessed May 5, 2018.

3. Mendoza RL. The 21st Century Cures Act: pharmacoeconomic boon or bane? J Med Econ. 2017;20(4):315-17.

4. Sarpatwari A, Kesselheim AS. The 21st Century Cures Act: opportunities and challenges. Clin Pharmacol Ther. 2015;98(6):575-77.

5. Meadows M. Promoting safe and effective drugs for 100 years. FDA Consumer Magazine. January-February 2006. Available at: https://www. fda.gov/downloads/AboutFDA/WhatWeDo/History/FOrgsHistory/CDER/ UCM586463.pdf. Accessed May 5, 2018.

6. McGinely L. Trump calls the FDA "slow and burdensome," but it's faster than ever. The Washington Post. March 2, 2017. Available at: https:// www.washingtonpost.com/news/to-your-health/wp/2017/03/02/trumpcalls-the-fda-slow-and-burdensome-but-its-faster-than-ever/?utm_term= aef25b96560f. Accessed May 5, 2018.

7. U.S. Food and Drug Administration. CDER approval times for priority and standard NDAs and BLAs calendar years 1993-2016. December 31, 2016. Available at: https://www.fda.gov/downloads/Drugs/ DevelopmentApprovalProcess/HowDrugsareDevelopedandApproved/ DrugandBiologicApprovalReports/NDAandBLAApprovalReports/ UCM540942.pdf. Accessed on May 19, 2018.

8. U.S. Food and Drug Administration. Prescription Drug User Fee Act (PDUFA). October 20, 2017. Available at: https://www.fda.gov/forindustry/ userfees/prescriptiondruguserfee/. Accessed May 5, 2018.

9. Patient-Centered Outcomes Research Institute. The PCORI Methodology Report. July 30, 2014. Available at: http://www.pcori.org/research-results/ research-methodology/pcori-methodology-report. Accessed May 5, 2018.

10. Schnipper LE, Davidson NE, Wollins DS, et al. Updating the American Society of Clinical Oncology Value Framework: revisions and reflections in response to comments received. J Clin Oncol. 2016;34(24):2925-34.

11. Fleming TR, Powers JH. Biomarkers and surrogate endpoints in clinical trials. Stat Med. 2012;31(25):2973-84. Available at: https://www.ncbi.nlm. nih.gov/pmc/articles/PMC3551627/. Accessed May 5, 2018.

12. U.S. Food and Drug Administration. Innovation at FDA. FDA facts: biomarkers and surrogate endpoints. July 22, 2016. Available at: https:// www.fda.gov/aboutfda/innovation/ucm512503.htm. Accessed May 5, 2018

13. Prinz F, Schlange T, Asadullah K. Believe it or not: how much can we rely on published data on potential drug targets? Nat Rev Drug Discov. 2011;10(9):712.

14. Prasad V, Kim C, Burotto M, Vandross A. The strength of association between surrogate end points and survival in oncology: a systematic review of trial-level meta-analyses. JAMA Intern Med. 2015;175(8):1389-98.

15. Svensson S, Menkes DB, Lexchin J. Surrogate outcomes in clinical trials: a cautionary tale. JAMA Intern Med. 2013;173(8):611-12.

16. Knopf K, Baum M, Shimp WS, et al. Interpretation of surrogate endpoints in the era of the 21st Century Cures Act. BMJ. 2016;355:i6286.

17. The Network for Excellence in Health Innovation. Real world evidence: a new era for health care innovation. Issue brief. September 2015. Available at: http://www.nehi.net/writable/publication_files/file/rwe_issue_brief_final. pdf. Accessed May 5, 2018.

18. Garrison LP Jr, Neuman PJ, Erickson P, et al. Using real-world data for coverage and payment decisions: the ISPOR real-world data task force report. Value Health. 2007;10(5):326-35. 
19. Berger ML, Sox H, Willke RJ, et al. Good practices for real-world data studies of treatment and/or comparative effectiveness: recommendations from the Joint ISPOR-ISPE Special Task Force on Real-World Evidence in Health Care Decision Making. Value Health. 2017;20(8):1003-08.

20. Wang SV, Schneeweiss S, Berger ML, et al. Reporting to improve reproducibility and facilitate validity assessment for healthcare database studies vl.0. Value Health. 2017;20(8):1009-22.

21. Azvolinsky A. Repurposing existing drugs for new indications. The Scientist. January 1, 2017. Available at: http://www.the-scientist. com/?articles.view/articleNo/47744/title/Repurposing-Existing-Drugs-forNew-Indications/. Accessed May 5, 2018.

22. Navarro RP. Changing the way we pay for health care: is value the new plastic? J Manag Care Spec Pharm. 2017;23(10):998-1002. Available at: https:// www.jmcp.org/doi/10.18553/jmcp. 2017.23.10.998.

23. Nazareth T, Ko JJ, Sasane R, et al. Outcomes-based contracting experience: research findings from U.S. and European stakeholders. J Manag Care Spec Pharm. 2017;23(10):1018-26. Available at: https://www.jmcp.org/ doi/10.18553/jmcp.2017.23.10.1018

24. Yeung K, Li M, Carlson JJ. Using performance-based risk-sharing arrangements to address uncertainty in indication-based pricing. J Manag Care Spec Pharm. 2017;23(10):1010-15. Available at: https://www.jmcp.org/ doi/10.18553/jmcp.2017.23.10.1010.
25. Yu J, Chin L, Oh J, Farias J. Performance-based risk-sharing arrangements for pharmaceutical products in the United States: a systematic review. J Manag Care Spec Pharm. 2017;23(10):1028-40. Available at: https://www. jmcp.org/doi/10.18553/jmcp.2017.23.10.1028.

26. Goble JA, Ung B, van Boemmel-Wegmann S, et al. Performance-based risk-sharing arrangements: U.S. payer experience. J Manag Care Spec Pharm. 2017;23(10):1042-52. Available at: https://www.jmcp.org/doi/10.18553/ jmcp.2017.23.10.1042.

27. Lee S, Manning M, Gertner H, Parsons N. 21st Century Cures offers more latitude to promote health care economic information, but ambiguities would remain. Hogan Lovells Focus on Regulation. December 5, 2016 Available at: http://www.hlregulation.com/2016/12/05/21st-century-curesoffers-more-latitude-to-promote-health-care-economic-information-butambiguities-would-remain/. Accessed May 5, 2018.

28. Perfetto EM, Burke L, Oehrlein EM, Gaballah M. FDAMA Section 114: Why the renewed interest? J Manag Care Spec Pharm. 2015;21(5):368-74. Available at: https://www.jmcp.org/doi/10.18553/jmcp.2015.21.5.368.

29. Centers for Disease Control and Prevention. About antimicrobial resistance. April 6, 2017. Available at: https://www.cdc.gov/drugresistance/about. html. Accessed May 5, 2018.

30. Avorn J, Kesselheim AS. The 21st Century Cures Act — will it take us back in time? N Engl J Med. 2015;372(26):2473-75. 